\title{
Highly selective vagotomy plus dilatation of the stenosis compared with truncal vagotomy and drainage in the treatment of pyloric stenosis secondary to duodenal ulceration
}

\author{
M. J. McMAhON, M. J. GREENALL, D. JOHNSTON ${ }^{1}$, AND J. C. GOLIGHER \\ From the University Department of Surgery, The General Infirmary, Leeds
}

SUMMARY Twenty-three consecutive patients with duodenal ulceration complicated by pyloric stenosis who came under the care of one surgeon were treated by highly selective vagotomy (HSV) combined with digital dilatation of the stenosis through a gastrotomy. No form of drainage procedure was used. Thus the antral 'mill' and the pyloric sphincter were left intact. Since the stenosis is usually distal to the pylorus rather than truly pyloric such dilatation does not damage the pyloric ring, although it may on occasion lead to perforation of the first part of the duodenum. The subsequent progress of these patients was compared with that of a similar, consecutive series of 23 patients with pyloric stenosis who were treated by truncal vagotomy with a drainage procedure by other surgeons on the same surgical unit. Patients were followed up for between four months and five years. The clinical assessment was carried out in 'blind' fashion at a special gastric follow-up clinic. No evidence of recurrent ulceration was found in either group of patients. Two patients from each group subsequently came to reoperation for the relief of gastric stasis. Twenty-two of the 23 patients $(96 \%)$ who had undergone HSV plus dilatation eventually achieved a good-to-excellent clinical result (Visick grades $1+2)$, whereas only 17 of the 23 patients $(74 \%)$ who had undergone truncal vagotomy with drainage achieved such a result. The main clinical difference between the two groups was that side effects such as diarrhoea and abdominal pain or discomfort were more common after vagotomy with drainage than after HSV. These results bear witness to the remarkable propulsive powers of the gastric antrum after HSV, which were evidently sufficient to overcome any tendency to re-stenosis in more than $90 \%$ of patients. The $9 \%$ incidence of failure due to re-stenosis could perhaps be avoided if a small duodenoplasty were performed instead of simple digital dilatation. The results support the hypothesis that damage to the antral mill and pyloric sphincter can be avoided in the course of operations for 'pyloric' stenosis secondary to duodenal ulceration. Avoidance of the drainage procedure is of benefit to the patient, just as it is in patients who have duodenal ulceration without stenosis.

When pyloric stenosis is secondary to duodenal ulceration the adjective 'pyloric' is not quite accurate, because in most patients the actual site of narrowing is beyond the pylorus in the first part of the duodenum. This distinction is important, because it means that the pyloric sphincter and the antral mill remain undamaged by the fibrosis, oedema, and spasm which combine to create the stenosis. As

${ }^{1}$ Address for correspondence: Professor ${ }^{*} D$. Johnston, University Department of Surgery, Bristol Royal Infirmary, Bristol.

Received for publication 19 February 1976 stenosis develops, the stomach compensates for the obstruction at its outlet by means of hypertrophy of its muscular wall and by forceful peristalsis in the antrum. Eventually, as stenosis becomes increasingly severe, the stomach gives up the unequal struggle, becoming dilated and atonic.

Although truncal vagotomy with a drainage procedure (TV $+D)$ is probably the most widelyused operation for pyloric stenosis, it wastes these compensatory mechanisms both by depriving the hypertrophied gastric musculature of its motor 
nerve supply and by destroying or bypassing the distal antrum and pylorus. The antral 'mill' and pyloric sphincter are resected entirely in the course of partial gastrectomy, which is the alternative 'standard' operative procedure.

Highly selective vagotomy (HSV), in contrast, keeps the antral mill and pyloric sphincter intact, and their motor nerve supply via the nerves of Latarjet is also preserved (Johnston and Wilkinson, 1970). Experience with HSV in Leeds and Copenhagen over the past seven years has shown that it yields better clinical results than TV $+D$ in the treatment of uncomplicated duodenal ulceration (Amdrup et al., 1974). Having found that gastric emptying was satisfactory after HSV in patients who had gross duodenal scarring without overt clinical signs of pyloric stenosis, we wondered whether preservation of the function of the hypertrophied antrum might be sufficient to ensure adequate gastric emptying even in patients who had clinical symptoms and signs of pyloric stenosis, provided that the stenosis was dilated at the time of operation. From 1971 onwards, one of the authors (D.J.) therefore employed HSV plus digital dilatation of the stenosis in the treatment of a consecutive series of patients with pyloric stenosis. The preliminary results were encouraging (Johnston et al., 1973a). Twenty-three patients have now been treated in this way and have been followed up for between four months and five years. The clinical results obtained in these patients have been compared with the results obtained in 23 patients with pyloric stenosis who were treated by TV $+D$ on the same surgical unit.

\section{Methods}

\section{PATIENTS}

All patients were treated in the University Department of Surgery at Leeds General Infirmary. HSV was used by one member of the staff (D.J.) to treat 23 consecutive patients with pyloric stenosis. Truncal vagotomy with a drainage procedure $(T V+D)$ was used as the standard operative procedure for patients with pyloric stenosis who came under the care of J.C.G. The most recent 23 patients who had undergone TV $+\mathrm{D}$ in the treatment of pyloric stenosis were reviewed and compared with the 23 patients who had undergone HSV. The two groups of patients were treated over approximately the same period of time. It is emphasised that no other method of selection of the operative procedure was used-that is, there was no question of mild cases of pyloric stenosis being treated by HSV, while more severe cases were treated by TV + D.

Patients were judged to have pyloric stenosis on the basis of a history of repeated vomiting, the presence of a succussion splash, evidence of gastric retention on barium meal examination, and the operative finding that the pylorus would not admit the index finger - we found, as did Kirk (1970), that a normal pylorus will admit the distal interphalangeal joint of the index finger, which is roughly equivalent to a No. 14 Hegar dilator. With one exception, all patients were found to have stenosis at operation. At least one of the other three features of pyloric stenosis listed above was present in each patient. In one patient who was treated by HSV there was good evidence of pyloric stenosis before operation, but at operation no evidence of pyloroduodenal narrowing was found. Obstruction of the gastric outlet in this patient was presumably due to the presence of an active chronic duodenal ulcer just distal to the pylorus and of an active chronic gastric ulcer immediately proximal to the pylorus. Muscle spasm and oedema around the pylorus no doubt gave rise to clinical and radiological signs of pyloric stenosis in this patient.

A comparison of the two groups of patients with respect to age, sex, length of ulcer history, and preoperative peak acid output is shown in Table 1.

\begin{tabular}{lll}
\hline & $H S V$ & $T V+D$ \\
\hline Age (yr) & $53 \cdot 6 \pm 2 \cdot 1$ & $53 \cdot 2 \pm 2 \cdot 6$ \\
Sex (M) & 14 & 16 \\
\multicolumn{1}{l}{ (F) } & 9 & 7 \\
$\begin{array}{l}\text { Length of ulcer history } \\
\text { (yr) }\end{array}$ & $16.7 \pm 2.3$ & $13.6 \pm 2.2$ \\
$\begin{array}{l}\text { Peak acid output } \\
\text { to pentagastrin }\end{array}$ & $40.9 \pm 4.4$ & $40.6 \pm 8.3$ \\
(mEq/h) & & \\
\hline
\end{tabular}

Table 1 Comparison of two groups of 23 patients with pyloric stenosis

Each patient had evidence of chronic duodenal ulceration at operation. In addition, a benign gastric ulcer was present in seven patients in the HSV group and in four patients in the TV $+D$ group. Advanced disease, indicated by radiological evidence of severe gastric retention and the operative finding of a large dilated stomach, was found in seven patients in the HSV group and in six patients in the TV + D group.

\section{OPERATIVE TECHNIQUE}

$H S V$ plus dilatation The first step is to perform a small longditudinal gastrotomy, near the greater curvature, just proximal to the antrum. This incision should not encroach upon the part of the stomach which is to be left innervated. The operator's right index finger is introduced into the antrum via the gastromy, insinuated through the pylorus, and gently dilates the stenotic segment until it will admit both the distal and the proximal interphalangeal joints, 
the latter being roughly equivalent to a No. 16 Hegar's dilator. Such dilatation produced frank perforation of the duodenal wall in four patients. These perforations were closed without difficulty with interrupted catgut sutures, which were placed in such a way as to widen the duodenal lumen. The gastrotomy is then closed with catgut and an HSV performed in the usual way (Johnston and Wilkinson, 1970; Johnston, 1975, 1976). The operation is usually delightfully easy in these patients because they are thin, with prominent nerves of Latarjet. About $8 \mathrm{~cm}$ of stomach were left innervated proximal to the pylorus rather than the 5 to $7 \mathrm{~cm}$ which are normally left innervated in the course of HSV for uncomplicated ulcer-firstly, because the stomach is usually dilated, so that the proportion of stomach left innervated may be little greater than usual, and, secondly, because it is particularly important in these patients to preserve the full vigour of antral peristalsis, in order to overcome any obstruction at the gastric outlet as the ulcer heals.

Management of coexisting gastric ulcer Such an ulcer is usually excised by a transgastric approach (Johnston et al., 1972) and confirmed to be benign by frozen section examination. The defect in the gastric mucosa is closed with catgut sutures. When the ulcer is near the pylorus, however, it is preferable merely to take several biopsies from its edge, because excision of the entire ulcer might produce narrowing at the gastric outlet.

Truncal vagotomy with a drainage procedure The drainage procedure employed was a gastrojejunostomy in 13 patients and a pyloroplasty in 10 patients. Eleven of the gastrojejunostomies were of the posterior, short-loop isoperistaltic variety and two were antecolic. Each was constructed with catgut in two layers. The stoma was approximately $6 \mathrm{~cm}$ in width and was situated near the most dependent part of the stomach, rather than in the prepyloric region. The pyloroplasties were of Heineke-Miculicz type in nine patients and of the Finney variety in one. The pyloroduodenal incision averaged $7-8 \mathrm{~cm}$ in length. Six of the pyloroplasties were sutured in one layer and four in two layers. Interrupted sutures of either catgut or silk were used for the one-layer closures, while in the two-layer closures the inner full-thickness layer of continuous catgut was reinforced by a further seromuscular layer of interrupted catgut or silk.

Tests of acid secretion Basal (BAO) and peak acid outputs to pentagastrin $\left(\mathbf{P A O}{ }^{\mathrm{Pg}}\right)$ were measured before and five to $\mathbf{1 0}$ days after operation (Johnston et al., 1973b) in 18 patients who underwent HSV and in seven patients who underwent $T V+D$. In addition, an insulin test was performed approximately one week after operation (Johnston et al., 1973c).

Clinical assessment All patients were assessed in 'blind' manner by a panel of doctors at a gastric follow-up clinic and placed in one of four grades (1, perfect; 2, good; 3, fair; and 4, poor) according to a modified Visick system (Visick, 1948; Goligher et al., 1968). The length of follow-up ranged from four months to five years. The mean length of follow-up was 24 months after HSV and 41 months after TV + D.

\section{Results}

OPERATIVE MORTALITY

There was no operative mortality in either group.

\section{ACID STUDIES}

After HSV, the mean reduction in BAO was $78 \%$ and in $\mathrm{PAO}^{\mathrm{Pg}}$ was $54 \%$, in 18 patients (Table 2). After $\mathrm{TV}+\mathrm{D}$ (seven patients only), the mean reduction in BAO was $76 \%$ and in PAOPg was $38 \%$ (Table 2 ). BAO and PAOPg after HSV did not differ significantly from BAO and $\mathrm{PAO}^{\mathrm{Pg}}$ after $\mathrm{TV}+\mathrm{D}$. The

\begin{tabular}{|c|c|c|c|c|c|c|}
\hline & \multicolumn{3}{|l|}{$\begin{array}{l}H S V \\
(23 \text { patients })\end{array}$} & \multicolumn{3}{|l|}{$\begin{array}{l}T V+D \\
(23 \text { patients })\end{array}$} \\
\hline & $\begin{array}{l}\text { Before } \\
\text { operation }\end{array}$ & $\begin{array}{l}\text { After } \\
\text { operation }\end{array}$ & $\begin{array}{l}\text { Percentage } \\
\text { reduction }\end{array}$ & $\begin{array}{l}\text { Before } \\
\text { operation }\end{array}$ & $\begin{array}{l}\text { After } \\
\text { operation }\end{array}$ & $\begin{array}{l}\text { Percentage } \\
\text { reduction }\end{array}$ \\
\hline $\mathrm{BAO}(\mathrm{mEq} / \mathrm{h})$ & $5 \cdot 9 \pm 1 \cdot 2$ & & $\begin{array}{l}78 \cdot 0 \\
(N=18)\end{array}$ & $7 \cdot 6 \pm 3 \cdot 0$ & & $\begin{array}{l}76 \cdot 3 \\
(N=7)\end{array}$ \\
\hline $\operatorname{PAO}^{P g}(\mathrm{mEq} / \mathrm{h})$ & $41 \cdot 5 \pm 4.8$ & $19 \cdot 2 \pm 2 \cdot 8$ & $\begin{array}{l}53.7 \\
(N=18)\end{array}$ & $42.2 \pm 9.2$ & $26 \cdot 2 \pm 6 \cdot 1$ & $\begin{array}{l}37 \cdot 9 \\
(\mathrm{~N}=7)\end{array}$ \\
\hline $\begin{array}{l}\text { Insulin test: } \\
\text { Post-operative }\end{array}$ & & (18 tests) & & & (14 tests) & \\
\hline $\begin{array}{l}\text { (1) Peak acid out- } \\
\text { put to insulin } \\
\text { (PAOI } ; \mathrm{mEq} / \mathrm{h})\end{array}$ & $\begin{array}{l}\text { Not } \\
\text { performed }\end{array}$ & $3 \cdot 1 \pm 1 \cdot 5$ & - & $\begin{array}{l}\text { Not } \\
\text { performed }\end{array}$ & $0.5 \pm 0.2$ & - \\
\hline $\begin{array}{l}\text { (2) Positive } \\
\text { results by Hollander's } \\
\text { criteria }\end{array}$ & - & $\begin{array}{l}\text { Early + ve } 1 \\
\text { Late + ve } 4 \\
\text { Negative } 13\end{array}$ & - & - & $\begin{array}{l}\text { Early + ve } 1 \\
\text { Late + ve } 0 \\
\text { Negative } 13\end{array}$ & - \\
\hline
\end{tabular}

Figures are arithmetical means plus or minus one standard error.

Table 2 Effects of highly selective vagotomy (HSV) and truncal vagotomy with drainage procedure (TV + D) on gastric acid output 
insulin test was positive by Hollander's (1948) criteria in five of 18 patients after HSV $(28 \%)$ and in one of 14 patients $(8 \%)$ after TV $+D$ (Table 2$)$. The mean peak acid response to insulin $\left(\mathrm{PAO}^{1}\right)$ was $3.1 \pm 1.5 \mathrm{mEq} / \mathrm{h}$ after $\mathrm{HSV}$ and $0.5 \pm 0.2 \mathrm{mEq} / \mathrm{h}$ after TV + D.

\section{RECURRENT ULCERATION}

Pain suggestive of recurrent ulceration was recorded in four patients after TV $+\mathbf{D}$ but in no patient after HSV. Barium meal examination and fibreoptic endoscopy showed no evidence of recurrent ulceration in any of these four patients. Six other patients complained of less specific types of abdominal pain after TV $+D$; none of the HSV patients complained of such pain.

\section{GASTRIC STASIS}

One patient from each group developed gastric retention in the early postoperative period and one patient from each group developed gastric retention several months after operation. The remaining patients made a good postoperative recovery, which was marred in a few of them by infection of the respiratory tract or of the wound.

\section{RE-OPERATION FOR STASIS AFTER HSV}

Case 1 S.B. Age 38 years. Male. It was noted at the time of operation that this patient had an enormously dilated stomach and a severe degree of duodenal stenosis. Twelve days after HSV and dilatation he began to vomit and on the 18th postoperative day a further laparotomy was carried out. The stomach was again found to be very dilated and an anterior gastrojejunostomy was added. After this he was still troubled by symptoms of gastric retention and he eventually came to a further laparotomy seven weeks later. The stomach was again found to be dilated and the gastrojejunostomy stoma appeared narrowed. The anastomosis was dismantled and a Finney pyloroplasty fashioned. Thereafter, progress was good and there was no further evidence of gastric retention. Six months after operation this patient was free from symptoms (Visick grade 1).

Case 2 E.S. Age 54 years. Male. At the time of HSV this man was found to have a dilated stomach and a tight stenosis. At first his postoperative progress was smooth but gastric retention gradually developed and further laparotomy became necessary 12 weeks later. The stomach was again found to be dilated and thick-walled and the 'pyloric' stenosis had re-formed. although there was no evidence of recurrent ulceration. This patient also achieved an excellent (Visick 1) result after the addition of a Heineke-Mikulicz pyloroplasty.
RE-OPERATION FOR STASIS AFTER TRUNCAL VAGOTOMY WITH DRAINAGE

Case 3 D.R. Age 35 years. Female. The initial operation was a truncal vagotomy and gastrojejunostomy. The stomach was noted to be dilated when this procedure was performed. A further laparotomy was performed nine days later because the gastric aspirates continued to be copious. The efferent limb of the gastrojejunostomy was found to be narrowed. The anastomosis was refashioned and, although gastric aspirates continued to be copious for several days, they eventually diminished. This patient too eventually achieved a Visick grade 1 result.

Case 4 G.W. Age 59 years. Female. A truncal vagotomy and Heineke-Miculicz pyloroplasty was performed, but further laparotomy was needed 10 months later because of persistent vomiting. The pyloroplasty was found to be narrowed and distorted, but there was no evidence of recurrent ulceration. A gastrojejunostomy was added, but 14 months later this had to be converted to a partial gastrectomy with Roux-en-Y anastomosis because of intractable bilious vomiting. This patient has consistenly had a Visick grade 4 (poor) result on clinical follow-up.

In addition to these four cases, clinical evidence of impaired gastric emptying was found in another two patients soon after HSV. In each of these patients, however, the distention and foul flatulence of which they complained resolved spontaneously in the course of several months.

\section{CLINICAL RESULTS}

Visick grades The overall results of operation as recorded at the patients' most recent visit to the gastric follow-up clinic are shown in Table 3. The results of reoperation have been incorporated in that table. Seventy-eight per cent of patients achieved a perfect (Visick grade 1) result after HSV, whereas only $44 \%$ of patients who had undergone TV + D achieved a perfect clinical result. Of the 10 patients

\begin{tabular}{|c|c|c|c|c|}
\hline Visick grade & \multicolumn{2}{|c|}{$\begin{array}{l}\text { HSV } \\
\text { (23 patients) }\end{array}$} & \multicolumn{2}{|c|}{$\begin{array}{l}T V+D \\
(23 \text { patients })\end{array}$} \\
\hline Perfect & & & & \\
\hline $\begin{array}{l}1 \\
\text { Very good }\end{array}$ & 18 & 78 & 10 & 44 \\
\hline & 22 & 96 & 17 & 74 \\
\hline $\begin{array}{l}3 \\
\text { Poor }\end{array}$ & 1 & 4 & 5 & 22 \\
\hline 4 & 0 & - & 1 & 4 \\
\hline
\end{tabular}

Table 3 Overall clinical results of operation in patients with pyloric stenosis as recorded at gastric follow-up clinic (results of any re-operations have been incorporated) 


\begin{tabular}{|c|c|c|c|c|}
\hline & \multicolumn{2}{|c|}{$H S V^{*}$} & \multicolumn{2}{|c|}{$T V+D^{*}$} \\
\hline & $\overline{(n o .)}$ & $\overline{(\%)}$ & $\overline{(n o .)}$ & $(\%)$ \\
\hline Early dumping & 3 & 13 & 4 & 17 \\
\hline Vomiting & 3 & 13 & 4 & 17 \\
\hline Flatulence & 3 & 13 & 8 & 35 \\
\hline Epigastric fullness & 4 & 17 & 9 & 39 \\
\hline Diarrhoea & i & 4 & 5 & 22 \\
\hline
\end{tabular}

* Number of patients 23.

Table 4 Side-effects of operation in patients with pyloric stenosis who were treated either by highly selective vagotomy (HSV) or by truncal vagotomy and drainage $(T V+D)$

with a Visick grade 1 result after TV $+D$, seven had a gastrojejunostomy as the drainage procedure and three had a pyloroplasty. Twenty-two of the 23 patients $(96 \%)$ eventually achieved a good-toexcellent result (Visick grade $1+2$ ) after HSV, whereas only 17 of 23 patients $(74 \%)$ achieved such a result after TV + D.

Side-effects of operation The incidences of various side-effects after HSV and TV + D are shown in Table 4. There was little difference between the respective incidences of early dumping and of vomiting, but diarrhoea, flatulence, and epigastric fullness were all much less common after HSV than after TV + D. Diarrhoea, for example, was noted in only one patient $(4 \%)$ after $\mathrm{HSV}$, compared with $22 \%$ of patients with TV + D.

\section{Discussion}

These findings demonstrate the remarkable propulsive powers of the gastric antrum when its vagal nerve supply is preserved, as in the operation of highly selective vagotomy. The gastric outlet became obstructed again in only two patients out of 23 after HSV plus a single dilatation of the stenosis, which is certainly surprising when one considers how liable to restenosis are fibrous strictures at other sites, such as urethra or oesophagus, when they are dilated only once. Admittedly, the 'pyloric' stenosis may have been due more to oedema and spasm than to the presence of fibrous tissue in perhaps one-third of the 23 patients, but in most patients the stenosis was felt at operation to be a hard, fibrous ring which had to be disrupted forcibly. It should also be emphasised that there was no question of only mild cases of pyloric stenosis being selected for the operation of HSV plus dilatation: the series of patients was consecutive, and represented about $12 \%$ of all patients coming to elective operation for duodenal ulcer. It is not clear why restenosis did not occur more often. We would speculate that the narrow duodenal passage was kept open by the vis-a-tergo imparted to the meal by antral peristalsis. The mean period of followup, two years, is of course short: however, if restenosis does not take place within six months of operation, it seems unlikely that it will do so later. This, then, was the main finding: that postoperative gastric emptying was satisfactory in $90 \%$ of patients with 'pyloric' stenosis after treatment by HSV plus a single digital dilatation of the stenosis.

Whether this operative method is the treatment of choice for such patients is debatable. One cannot be complacent about the $9 \%$ of patients (two of 23) who came to further laparotomy on account of restenosis, and it should be borne in mind also that a further two patients had impaired gastric emptying for several months after operation, although luckily in the long run their symptoms abated spontaneously. This raises the question of whether the 10 to $20 \%$ of patients in whom the procedure is liable to fail could be identified before operation and treated by vagotomy with a drainage procedure. While such an idea is attractive in theory, it is probably impractical. Although three of the four patients whose gastric emptying was delayed after HSV had severe pyloric stenosis, many other patients with what semed to be an equally severe degree of stenosis showed no evidence of impaired gastric emptying after HSV plus dilatation. An alternative approach to the problem has been described by Kennedy (1976) who, instead of digital dilatation in such patients, performs HSV plus a small duodenoplasty, distal to the pyloric ring. In a series of patients similar to our own, he has had no failures due to gastric retention. On the other hand, such duodenoplasties, when carried out in the presence of oedema and fibrosis, could be both difficult to perform and not devoid of the risk of duodenal fistulation. Finally, it should be mentioned that, even after vagotomy with a drainage procedure, gastric emptying is by no means invariably satisfactory (Kennedy et al., 1973). The findings of poor gastric emptying in $9 \%$ of patients after TV $+\mathrm{D}$ in our series may be unrepresentative, but there is no doubt that gastric retention can occur after both pyloroplasty and gastrojejunostomy, the latter procedure particularly being associated with a wide variety of potential mechanical complications, such as kinking of the loop, retrograde intussusception, and excessive reflux of bile into the stomach. Thus, while HSV plus dilatation has been shown to fail in $10 \%$ of patients, a drainage procedure (with vagotomy) probably also fails to produce satisfactory gastric emptying in about $5 \%$ of patients.

Seventy-four per cent of patients were found to have achieved perfect clinical results after HSV, whereas only $44 \%$ of patients after TV + D did so: $94 \%$ of patients had good-or-excellent results (Visick 
grades $1+2$ ) after HSV, compared with only $74 \%$ of patients after TV + D. These findings, while they might appear at first sight to give an unfair account of the clinical results to be expected after TV + D (Feggetter and Pringle, 1965; Ellis et al., 1966), are, in fact, very similar to those which were reported previously from Leeds after HSV and TV + D when these procedures were used in the treatment of patients with uncomplicated duodenal ulceration (Goligher et al., 1968; 1972; Amdrup et al., 1974). The comparison between HSV and TV $+D$ in this study is greatly weakened, however, by the facts that patients were not allotted in random manner to one or other of the operative procedures and that the length of follow-up of patients after HSV (24 months) was considerably shorter than that of patients who had undergone TV + D (41 months). Thus the study could be biased, either in favour of TV $+\mathrm{D}$ or against it, and quite clearly a controlled, prospective evaluation of HSV plus dilatation or duodenoplasty versus $T V+D$ in the treatment of patients with pyloric stenosis is now required. In such a trial, we would suggest that elderly or decrepit patients should probably be excluded, because they would be less well able to withstand a second operation should restenosis occur after HSV plus dilatation.

We thank Dr B. E. Walker, University Department of Medicine, St. James' Hospital, Leeds, for help with the clinical assessment. M. J.G. was supported by a grant from the Endowment Fund, Leeds General Infirmary.

\section{References}

Amdrup, E., Jensen, H-E., Johnston, D., Walker, B. E., and Goligher, J. C. (1974). Clinical results of parietal cell vagotomy (highly selective vagotomy) two to four years after operation. Annals of Surgery, 180, 279-284.

Ellis, H., Starer, F., Venables, C., and Ware, C. (1966). Clinical and radiological study of vagotomy and gastric drainage in the treatment of pyloric stenosis due to duodenal ulceration. Gut, 7, 671-676.

Feggetter, G. Y., and Pringle, R. (1965). The relationship between the severity of duodenal ulceration and the results of bilateral vagotomy and gastrojejunostomy. British Journal of Surgery, 52, 691-693.
Goligher, J. C., Pulvertaft, C. N., De Dombal, F. T., Conyers, J. H., Duthie, H. L., Feather, D. B., Latchmore, A. J. C., Shoesmith, J. H., Smiddy, F. G., and Willson-Pepper, J. (1968). Five- to eight-year results of Leeds/York controlled trial of elective surgery for duodenal ulcer. British Medical Journal, 2, 781-787.

Goligher, J. C., Pulvertaft, C. N., Irvin, T. T., Johnston, D., Walker, B.E., Hall, R. A.,Willson-Pepper, J., and Matheson, T. S. (1972). Five- to eight-year results of truncal vagotomy and pyloroplasty for duodenal ulcer. British Medical Journal, 1, 7-13.

Hollander, F. (1948). Laboratory procedures in the study of vagotomy (with particular reference to the insulin test). Gastroenterology, 11, 419-425.

Johnston, D. (1975). Highly selective vagotomy. Progress in Surgery, 14, 1-45.

Johnston, D. (1976). Vagotomy and drainage procedures. British Journal of Hospital Medicine, 15, 277-288.

Johnston, D., Humphrey, C. S., Smith, R. B., and Wilkinson, A. R. (1972). Treatment of gastric ulcer by highly selective vagotomy without a drainage procedure: an interim report. British Journal of Surgery, 59, 787-792.

Johnston, D., Lyndon, P. J., Smith, R. B., and Humphrey, C. S. (1973a). Highly selective vagotomy without a drainage procedure in the treatment of haemorrhage, perforation, and pyloric stenosis due to peptic ulcer. British Journal of Surgery, 60, 790-797.

Johnston, D., and Wilkinson, A. R. (1970). Highly selective vagotomy without a drainage procedure in the treatment of duodenal ulcer. British Journal of Surgery, 57, 289-296.

Johnston, D., Wilkinson, A. R., Humphrey, C. S., Smith, R. B., Goligher, J. C., Kragelund, E., and Amdrup, E. (1973b). Serial studies of gastric secretion in patients after highly selective (parietal cell) vagotomy without a drainage procedure for duodenal ulcer. 1 . Effect of highly selective vagotomy on basal and pentagastrin-stimulated maximal acid output. Gastroenterology, 64, 1-11.

Johnston, D., Wilkinson, A. R., Humphrey, C. S., Smith, R. B., Goligher, J. C., Kragelund, E., and Amdrup, E. (1973c). Serial studies of gastric secretion in patients after highly selective (parietal cell) vagotomy without a drainage procedure for duodenal ulcer. 2 . The insulin test after highly selective vagotomy. Gastroenterology, 64, 12-21.

Kennedy, T. (1976). Duodenoplasty with proximal gastric vagotomy. Annals of the Royal College of Surgeons of England, 58, 144-146.

Kennedy, F., MacKay, C., Bedi, B. S., and Kay, A. W. (1973). Truncal vagotomy and drainage for chronic duodenal ulcer disease: a controlled trial. British Medical Journal, 2 , 71-75.

Kirk, R. M. (1970). The size of the pyloroduodenal canal: its relation to the cause and treatment of peptic ulcer. Proceedings of the Royal Society of Medicine, 63, 944-946.

Visick, A. H. (1948). A study of the failures after gastrectomy. Annals of the Royal College of Surgeons of England, 3, 266284. 